\title{
New Highly-Sensitive Ultra-Performance Liquid Chromatography - Mass Spectrometry Method for Quantification of Telmisartan in Human Plasma
}

\author{
Tanveer A Wani ${ }^{1 *}$ and Seema Zargar ${ }^{2}$ \\ ${ }_{1}^{1}$ Department of Pharmaceutical Chemistry, College of Pharmacy, King Saud University, PO Box 2457, Riyadh 11451, \\ ${ }^{2}$ Department of Biochemistry, College of Science, King Saud University, PO Box 22452, Riyadh 11211, Saudi Arabia \\ *For correspondence: Email: tanykash@yahoo.co.in; twani@ksu.edu.sa
}

Received: 1 November 2014

Revised accepted: 20 February 2015

\begin{abstract}
Purpose: To develop and validate a simple, rapid, sensitive and specific ultraperformance liquid chromatography mass spectrometry method for the quantification of the angiotensin II receptor antagonist, telmisartan (TEL), in human plasma.

Methods: After simple protein precipitation using acetonitrile and methanol, TEL and internal standard (IS) abiraterone were separated on Acquity UPLC BEH ${ }^{T M}$ C18 column $(50 \times 2.1 \mathrm{~mm}$, i.d. $1.7 \mu \mathrm{m}$, Waters, USA) using a mobile phase consisting of acetonitrile: $8 \mathrm{mM}$ ammonium acetate containing 0.15 $\%$ formic acid ( $\mathrm{v} / \mathrm{v}$ ) (70:30) pumped at a flow rate of $0.3 \mathrm{~mL} / \mathrm{min}$ and detected by tandem mass spectrometry with positive ion mode. The ion transitions recorded in multiple reaction monitoring mode were $\mathrm{m} / \mathrm{z}$ 515.27 $\rightarrow 276.13$ for telmisartan and $\mathrm{m} / \mathrm{z} 350.1>156.0$ for internal standard, abiraterone.

Results: The assay exhibited a linear dynamic range of $1-200 \mathrm{ng} / \mathrm{mL}$ for telmisartan in human plasma with good correlation coefficient (0.995) and limit of quantitation of $1 \mathrm{ng} / \mathrm{mL}$. The relative standard deviation for the intra- and inter-assay precision was between $0.75-11.50$

Conclusion: The developed UPLC-MS/MS method is simple, rapid and highly sensitive, and should thus be suitable for pharmacokinetic and toxicokinetic studies in both animals and humans.
\end{abstract}

Keywords: Telmisartan, Ultra-Performance liquid chromatography, Tandem mass spectrometry, Pharmacokinetics, Toxicokinetics, High throughput analysis

Tropical Journal of Pharmaceutical Research is indexed by Science Citation Index (SciSearch), Scopus, International Pharmaceutical Abstract, Chemical Abstracts, Embase, Index Copernicus, EBSCO, African Index Medicus, JournalSeek, Journal Citation Reports/Science Edition, Directory of Open Access Journals (DOAJ), African Journal Online, Bioline International, Open-J-Gate and Pharmacy Abstracts

\section{INTRODUCTION}

Telmisartan TEL (4-((2-n-propyl-4-methyl-6-(1methylbenzimidazol-2-yl)-benzimidazol-1-

yl)methyl)-biphenyl-2-carboxylic acid) is an angiotensin II receptor antagonist widely used in the treatment of hypertension and heart failure (Figure 1). It undergoes minimal biotransformation in the liver to form the inactive telmisartan 1-o-acylglucuronide as its principal metabolite. The long half-life and selectivity of telmisartan for angiotensin II receptors allows once daily dosing with minimal side effects $[1,2]$. There are different mechanisms: increasing the activity of the sympathetic nervous system, causing a boosted sodium revertive resorption in the kidneys and promotion of the secretion of aldosterone in the adrenal glands [3]. The most recent clinical trials demonstrated that telmisartan also has preventive roles against ischemic heart diseases in diabetic patients with a similar potency to angiotensin converting enzyme inhibitor [4]. Several studies recently suggest that the effects of telmisartan are 
mediated via not only blockade of AT1R but also activation of peroxisome proliferators-activated receptor (PPAR)-y [5].

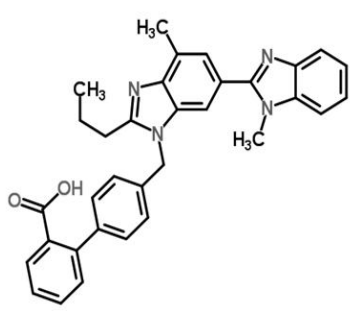

TELMISARTAN $[A]$

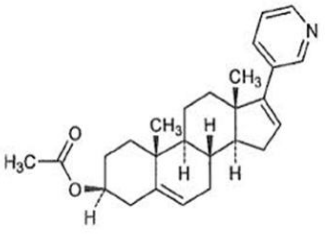

ABIRATERONE [B]
Figure 1: Chemical structure of telmisartan $[A]$ and abiraterone (IS) [B]

The literature reveals that there are a plethora of analytical methods reported for the quantitative determination of TEL in bulk, pharmaceutical formulations and biomatrices mainly based on high performance-liquid chromatography (HPLC) [6-10] and liquid chromatography-tandem mass spectrometry (LC/MS/MS) [11-13]. Other methods developed for the determination of telmisartan include immunoassay [14]. In general, immunoassays lack specificity and cannot distinguish multiple analytes or active metabolites or degradation products from the parent compound. Although HPLC-MS/MS method can provide excellent sensitivity, however, UPLC-MS/MS provide even more significant reduction in analysis time and solvent consumption. The reported HPLC methods used column switching or tedious and expensive solid phase extraction methods or longer run time.

UPLC is a new category of separation science which builds upon well-established principles of liquid chromatography, using sub-2 $\mu \mathrm{m}$ porous particles. These particles operate at elevated mobile phase linear velocities to produce significant reductions in separation time and solvent consumption. Literature indicates that a UPLC system allows approximately nine fold decreases in analysis time as compared to the conventional high-performance (HP) LC system using $5 \mu \mathrm{m}$ particle size analytical columns, and approximately threefold decrease in analysis time in comparison with $3 \mu \mathrm{m}$ particle size analytical columns without compromise on overall separation [15-21].

The objective of the present study was to develop and validate an UPLC method coupled with tandem mass spectrometry (UPLC-MS/MS) for the determination of TEL in human plasma.

\section{EXPERIMENTAL}

TEL was obtained from AK Scientific Inc. (CA, USA). Abiraterone was obtained from Selleck Chem in Houston, TX, USA. Human plasma was obtained from normal healthy volunteers at King Khalid University Hospital (Riyadh, Saudi Arabia), and the ethical approval of the study was obtained from the institutional review board of the King Khalid University Hospital. The samples were kept frozen at $-20{ }^{\circ} \mathrm{C}$ until analysis. HPLC-grade acetonitrile, methanol and ammonium acetate were obtained from Winlab Laboratory, UK. Formic acid was obtained from BDH Laboratory, UK. All other reagents were of analytical grade unless stated otherwise. All aqueous solutions was prepared using water that was purified using Milli-QR Gradient A10R (Millipore, Moscheim Cedex, France) having pore size $0.22 \mu \mathrm{m}$.

\section{Apparatus and operating condition}

\section{Liquid chromatography}

The UPLC system included quaternary solvent manager, a binary pump, degasser, autosampler with an injection loop of $10 \mu \mathrm{L}$ and a column heater-cooler. The separation was performed on Acquity UPLC BEH ${ }^{\mathrm{TM}} \mathrm{C} 18$ column $(50 \square 2.1 \mathrm{~mm}$, i.d., $1.7 \mu \mathrm{m}$, Waters, USA) maintained at $25^{\circ} \mathrm{C}$. The mobile phase was composed of acetonitrile: $8 \mathrm{mM}$ ammonium acetate containing $0.15 \%$ formic acid ( $\mathrm{v} / \mathrm{v})(70: 30)$ pumped at a flow rate of $0.3 \mathrm{~mL} / \mathrm{min}$. The injection volume was $5 \mu \mathrm{L}$ in partial loop mode and the temperature of the autosampler was kept at $8{ }^{\circ} \mathrm{C}$.

\section{Mass spectrometric conditions}

Waters Acquity liquid chromatography system coupled with a Waters TQD triple quadrupole mass spectrometer was used (Waters, Milford, USA). Mass spectrometric detection was carried out using an electrospray interface (ESI) operated in the positive ionization mode with multiple reaction monitoring (MRM) for both TEL and IS. Nitrogen was used as a desolvating gas at a flow rate of $500 \mathrm{~L} / \mathrm{h}$. The desolvating temperature was set at $450{ }^{\circ} \mathrm{C}$ and the source temperature was set at $150^{\circ} \mathrm{C}$. The collision gas (argon) flow was set at $0.1 \mathrm{~mL} / \mathrm{min}$. The capillary voltage was set at $3.50 \mathrm{kV}$. The MS analyzer parameters were as follows: LM1 and HM1 resolution 12.0 and 12.0; ion energy $1,1.0 \mathrm{~V}$; LM2 and HM2 resolution 14.0 and 14.0 respectively, ion energy $2,0.1 \mathrm{~V}$, dwell time, $0.146 \mathrm{~s}$. The cone voltage and collision energy were optimized in case of each analyte so as to maximize the signal corresponding to the major 
transition observed in the MS/MS spectra, following the fragmentation of the $[\mathrm{M}+\mathrm{H}]^{+}$ions corresponding to the selected compounds. Mass resolution is automatically adjusted by intellistart software embedded in the Mass Lynx software to desired resolution. Mass Lynx software (Version 4.1, SCN 805) was used to control the UPLCMS/MS system as well as for data acquisition and processing.

\section{Calibration standards and quality control samples}

Standard stock solutions of TEL and abiraterone (IS), respectively, were prepared by dissolving the compounds in methanol, to give a final concentration of $1 \mathrm{mg} / \mathrm{mL}$. The $1 \mathrm{mg} / \mathrm{mL}$ stock solution of TEL was serially diluted to prepare working solutions in the required concentration range with diluent methanol-water (50:50, v/v). The calibration standards and quality control (QC) samples were prepared by spiking (5\% of the total plasma volume) with working solutions yielding concentration range from 1 to $200 \mathrm{ng} / \mathrm{mL}$ for TEL. The final concentrations for each analyte were prepared to be $1,2,4,8,16,30,50,90$, 100, $200 \mathrm{ng} / \mathrm{mL}$. QC stock solutions for TEL were prepared separately in methanol-water (50:50, $\mathrm{v} / \mathrm{v})$. QC samples at four different concentrations levels: $1 \mathrm{ng} / \mathrm{mL}$ lower limit of quantitation (LLOQ), $2 \mathrm{ng} / \mathrm{mL}$ low quality control (LQC) (LQC, within three times of the LLOQ), $80 \mathrm{ng} / \mathrm{mL}$ middle quality control (MQC) and $160 \mathrm{ng} / \mathrm{mL}$ high quality control (HQC) were prepared in a similar manner as the calibration standards. Spiked plasma calibration standards and quality control samples were kept at $-80{ }^{\circ} \mathrm{C}$ until assayed or used for validating the assay procedures. The IS working solution $(1 \mu \mathrm{g} / \mathrm{mL})$ for routine use was prepared by diluting the abiraterone stock solution in methanol and kept in refrigerator for storage. Plasma blank: $200 \mu \mathrm{L}$ of plasma was spiked with $20 \mu \mathrm{L}$ of methanol-water (50:50, v/v). Plasma blank with internal standard: $200 \mu \mathrm{L}$ of plasma was spiked with $10 \mu \mathrm{L}$ of methanol-water (50:50, $\mathrm{v} / \mathrm{v}$ ) and $10 \mu \mathrm{L}$ of $1 \mu \mathrm{g} / \mathrm{mL} \mathrm{IS}$.

\section{Sample preparation}

A simple protein precipitation method was used to extract telmisartan and the internal standard. Plasma samples stored at around $-80{ }^{\circ} \mathrm{C}$ were thawed, left for 1 hour and vortexed for $30 \mathrm{sec}$ on room temperature before extraction to ensure homogeneity. To $200 \mu \mathrm{L}$ of plasma sample, 10 $\mu \mathrm{L}(1 \mu \mathrm{g} / \mathrm{mL})$ of IS was added. The samples were vortex mixed for about $30 \mathrm{~s}$ and then 150 $\mu \mathrm{L}$ of methanol was added to it and vortex mixed again for another 30 seconds. After vortex mixing further $500 \mu \mathrm{L}$ of acetonitrile was added to the sample. The samples were again vortex mixed gently for $1.5 \mathrm{~min}$ and the supernatant was separated after centrifugation at $15000 \mathrm{~g}$ for 10 min and evaporated to dryness under a gentle stream of nitrogen at $40{ }^{\circ} \mathrm{C}$. The residue was reconstituted with $200 \mu \mathrm{L}$ of mobile phase methanol-water (50:50, v/v) and transferred to UPLC vials. $5 \mu \mathrm{L}$ volumes (in partial loop with needle over fill mode) of the sample were subjected to the analysis by UPLC-MS/MS.

\section{Bioanalytical method validation}

A full method validation was performed according to guidelines set by the United States Food and Drug Administration (US-FDA) and European Medicines Agency (EMEA) guidelines [22,23].

\section{Selectivity and specificity}

The selectivity of the method towards endogenous plasma matrix components, metabolites and component medications was assessed in human blank plasma. Among the analyzed plasma batches, plasma batch showing no or minimal interference at the retention time of analytes and internal standards was selected. They were processed and analyzed using the proposed extraction protocol spiked with standard TEL at lower limit of quantification (LLOQ) level ( $1 \mathrm{ng} / \mathrm{mL}$ ) and IS $50 \mathrm{ng} / \mathrm{mL}$.

\section{Linearity and standard curve}

The linearity of the method was determined by analysis of standard plots associated with ten point standard calibration curve $(1-200 \mathrm{ng} / \mathrm{mL}$ ). Calibration curves from accepted three precision and accuracy batches were used to establish linearity. Curves were best fitted using a least square linear regression model $y=m x+b$, weighted by $1 / x^{2}$, in which $y$ is the peak area ratio, $m$ is slope of the calibration curve, $b$ is the $y$-axis intercept of the calibration curve and $x$ is the analyte (TEL) concentration. Backcalculations were made from these curves to determine the concentration of TEL in each calibration standards and the resulting calculated parameters were used to determine concentrations of analyte in quality control samples. The determination coefficient $r^{2}>0.996$ was desirable for all the calibration curves. The lowest standard on the calibration curve was to be accepted as the lower limit of quantification LLOQ.

\section{Precision and accuracy}

Intra- and inter-day accuracies expressed as a percentage of deviation from the respective 
nominal value. The precision of the assay was measured by the percent coefficient of variation (\% CV) at four concentrations in human plasma. Intra-day precision and accuracy were assessed by analyzing six replicates of the quality control samples at four levels (quality control) during a single analytical run. The inter-day precision and accuracy were assessed by analyzing 18 replicates of the quality control samples at each level through three precision and accuracy batches runs on 3 consecutive validation days.

\section{Extraction recovery and matrix effect}

To investigate extraction recovery, a set of samples ( $n=6$ at each low, medium, and high concentration levels in unique lots of plasma) was prepared by spiking telmisartan into plasma at 2, 80, and $160 \mathrm{ng} / \mathrm{mL}$, respectively. Each of the samples were processed as per the procedure described previously. A second set of plasma samples was processed and spiked postextraction with the same concentrations of telmisartan and IS that actually existed in the pre-extraction spiked samples. Extraction recovery for each analyte was determined by calculating the ratios of the raw peak areas of the pre-extraction spiked samples to those of the samples spiked after extraction. The matrix effect was evaluated by analyzing MQC sample.

\section{Stability and dilution integrity evaluation}

Stability of TEL in plasma was assessed by analyzing six replicates of QC samples at low and high concentrations under a variety of storage and processing conditions. Six aliquots of each low and high concentration quality control samples were taken to evaluate the bench top stability (short term stability), freeze thaw stability, auto sampler storage stability and long term stability. Bench-top stability was assessed after exposure of the plasma samples to room temperature for $\sim 6 \mathrm{~h}$, which exceeds the residence time of the sample processing procedures. The freeze-thaw stability was evaluated after undergoing three freeze (at around $-80{ }^{\circ} \mathrm{C}$ ) thaw (room temperature) cycles. The autosampler storage stability was determined by storing the reconstituted QC samples for $\sim 48 \mathrm{~h}$ under autosampler condition (maintained at $8{ }^{\circ} \mathrm{C}$ ) before being analyzed. Long-term stability was assessed after storage of the test samples at around $-80{ }^{\circ} \mathrm{C}$ for 60 days. The working solutions and stock solutions of TEL and the IS were also evaluated for stability at room temperature for $24 \mathrm{~h}$ and at refrigerator temperature (below $10{ }^{\circ} \mathrm{C}$ ) for 25 days. All stability exercises were performed against freshly spiked calibration standards. The dilution integrity experiment was intended to validate the dilution test to be carried out on higher analyte concentrations (above ULOQ), which may be encountered during real subject samples analysis.

\section{RESULTS}

The best chromatographic conditions were achieved with mobile phase comprising acetonitrile: $8 \mathrm{mM}$ ammonium acetate containing $0.15 \%$ formic acid (v/v) (70:30) pumped at a flow rate of $0.30 \mathrm{~mL} / \mathrm{min}$, on a C18 column (50 $\square 2.1$ $\mathrm{mm}$ i.d., $1.7 \mu \mathrm{m})$. The selected conditions were found to be suitable for the determination of electrospray response for TEL and IS (Figure 2). The method was found to be linear from 1 to 200 $\mathrm{ng} / \mathrm{mL}$ for TEL in human plasma. The determination coefficients $\left(r^{2}\right)$ were consistently greater than 0.995 during the course of validation. The lower limit of quantification for this assay was $1 \mathrm{ng} / \mathrm{mL}$ in plasma. Table 1 summarizes the inter- and intra-day precision and accuracy values for QC samples. The coefficient of variation values of both intra- and inter- day results of plasma were $3.80-11.50 \%$ and $0.75-2.74 \%$, respectively. TEL showed an average $(n=6)$ matrix factor of $99.12 \%$ at MQC level with a CV of $4.11 \%$.

The stability results, summarized in Table 2, showed that TEL spiked into human plasma was stable for at least $6 \mathrm{~h}$ at room temperature, for at least $48 \mathrm{~h}$ in final extract at $8{ }^{\circ} \mathrm{C}$ under autosampler storage condition, for 25 days at around $-80{ }^{\circ} \mathrm{C}$, and during three freeze-thaw cycles when stored at around $-80{ }^{\circ} \mathrm{C}$ and thawed to room temperature. The stock solutions and working standard of TEL and IS were stable for 25 days at refrigerator temperature (below $10{ }^{\circ} \mathrm{C}$ ) and at least for $24 \mathrm{~h}$ at room temperature. In dilution integrity study, accuracy of the 2- and 4fold diluted samples was 97.27 and $97.82 \%$ of the nominal concentration for TEL. At three QC concentration levels (2, 80 and $160 \mathrm{ng} / \mathrm{mL})$, the percent extraction recoveries (mean \pm SD) of TEL obtained are given in Table 3 . The mean extraction recovery for TEL was $82.12 \pm 2.38 \%$, and for the IS abiraterone at the concentration employed, it was $88.69 \pm 4.33 \%$. 


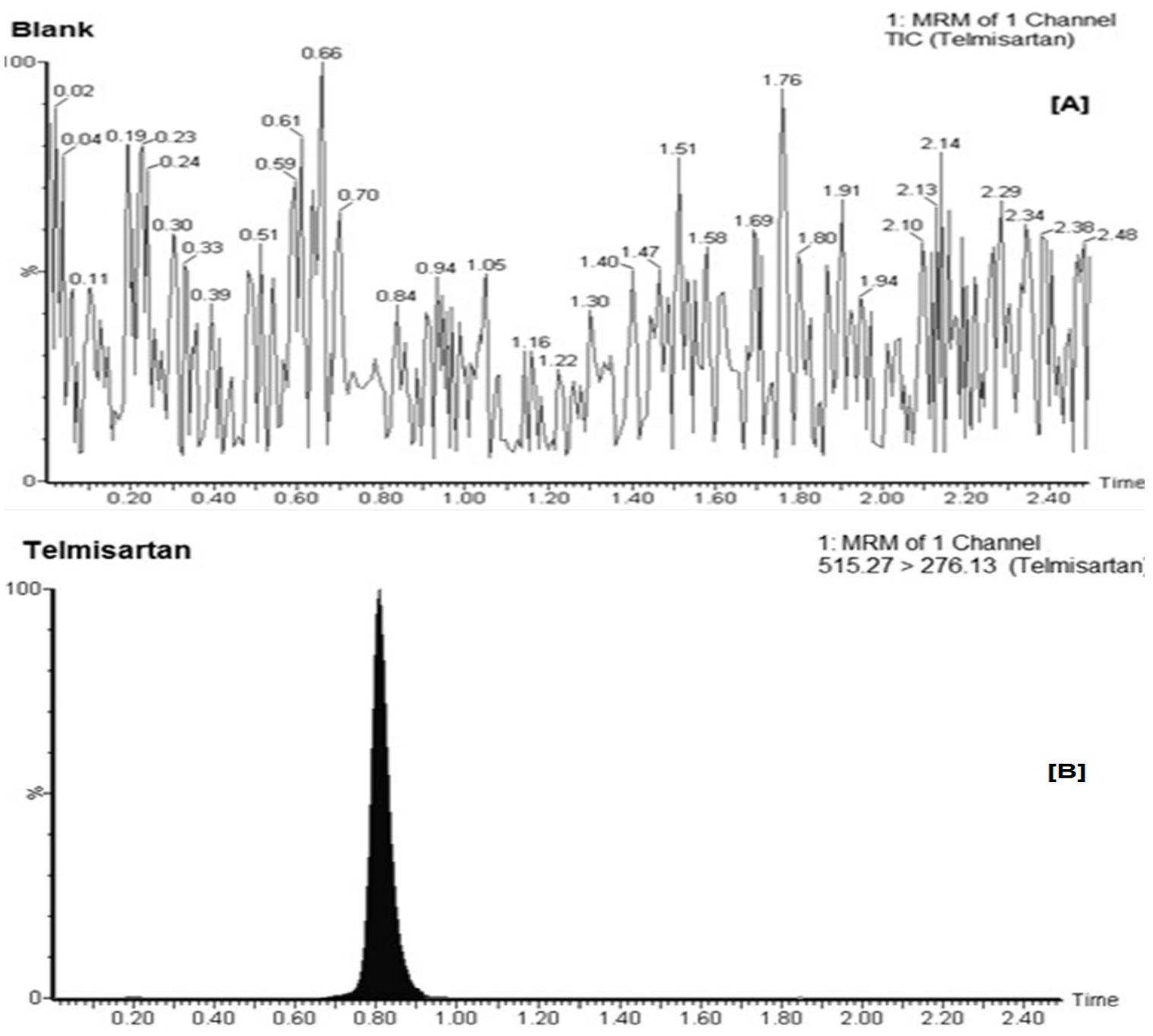

Figure 2: (A) Representative chromatograms of blank, $[B]$ Representative chromatograms of HQC of TEL in human plasma

Table 1: Intra- and inter-day precision and accuracy of TEL in human plasma

\begin{tabular}{|c|c|c|c|}
\hline $\begin{array}{l}\text { Nominal conc. } \\
\text { (ng/mL) }\end{array}$ & Run & Human plasma & \\
\hline & & red conc. (ng/mL $\pm S D)$ & Precision (RSD) \\
\hline \multicolumn{4}{|c|}{ Intraday variation ( $n=6$ at each concentration) } \\
\hline \multirow[t]{3}{*}{1} & 1 & $1.00 \pm 0.06$ & 6.77 \\
\hline & 2 & $0.95 \pm 0.10$ & 11.50 \\
\hline & 3 & $0.99 \pm 0.09$ & 9.50 \\
\hline \multirow[t]{3}{*}{2} & 1 & $2.04 \pm 0.15$ & 7.36 \\
\hline & 2 & $1.97 \pm 0.14$ & 7.48 \\
\hline & 3 & $2.08 \pm 0.14$ & 6.76 \\
\hline \multirow[t]{3}{*}{80} & 1 & $82.51 \pm 4.54$ & 5.50 \\
\hline & 2 & $80.15 \pm 6.16$ & 7.76 \\
\hline & 3 & $81.00 \pm 3.90$ & 4.82 \\
\hline \multirow[t]{3}{*}{160} & 1 & $165.91 \pm 6.30$ & 3.80 \\
\hline & 2 & $164.12 \pm 6.50$ & 3.96 \\
\hline & 3 & $163.50 \pm 7.09$ & 4.33 \\
\hline \multicolumn{4}{|c|}{ Interday variation ( $n=18$, at each concentration) } \\
\hline 1 & & $0.98 \pm 0.02$ & 2.56 \\
\hline 2 & & $2.03 \pm 0.05$ & 2.74 \\
\hline 80 & & $81.22 \pm 1.19$ & 1.46 \\
\hline 160 & & $164.51 \pm 1.24$ & 0.75 \\
\hline
\end{tabular}


Table 2: Stability and dilution integrity data of TEL in human plasma

\begin{tabular}{lccc}
\hline $\begin{array}{l}\text { Stability } \\
(\mathbf{n}=\mathbf{6})\end{array}$ & $\begin{array}{c}\text { Nominal conc. } \\
(\mathbf{n g} / \mathbf{m L})\end{array}$ & $\begin{array}{c}\text { Measured conc. }(\mathbf{n g} / \mathbf{m L} \mathbf{\pm} \\
\mathbf{S D})\end{array}$ & Precision (RSD) \\
\hline Bench top $(6 \mathrm{~h})$ & 2 & $2.02 \pm 0.15$ & 7.48 \\
& 160 & $158.29 \pm 7.32$ & 4.62 \\
Freeze thaw $(3$ cycle) & 2 & $2.00 \pm 0.12$ & 6.45 \\
& 160 & $161.67 \pm 7.14$ & 4.41 \\
Auto sampler $(48 \mathrm{~h})$ & 2 & $1.97 \pm 0.11$ & 7.15 \\
& 160 & $166.32 \pm 6.48$ & 4.02 \\
25 days at $-80^{\circ} \mathrm{C}$ & 2 & $1.96 \pm 0.16$ & 5.89 \\
& 160 & $159.02 \pm 5.68$ & 3.97 \\
Dilution integrity & 80 & $77.82 \pm 6.36$ & 6.59 \\
& 160 & $156.52 \pm 8.09$ & 4.99 \\
\hline
\end{tabular}

Table 3: Extraction recovery data of TEL (three QC samples) and abiraterone in human plasma

\begin{tabular}{lcc}
\hline Compound & Nominal conc. $(\mathbf{n g} / \mathbf{m L})$ & Recovery $(\% \pm \mathbf{S D})$ \\
\hline TEL (analyte) & 2 & $79.58 \pm 7.13$ \\
& 80 & $82.47 \pm 6.13$ \\
& 160 & $84.31 \pm 8.13$ \\
Abiraterone (IS) & Mean \pm SD & $82.12 \pm 2.38$ \\
\hline
\end{tabular}

\section{DISCUSSION}

Initial feasibility experiments of various mixture(s) of organic solvents such as acetonitrile and methanol along with millipore water; both having $0.1 \%$ formic acid, also these organic solvents along with different concentration of ammonium acetate $(2-15 \mathrm{mM})$ with altered flow-rates (in the range of $0.20-0.50 \mathrm{~mL} / \mathrm{min}$ ) was performed to optimize an effective chromatographic conditions of TEL and IS. UPLC-MS/MS operation parameters were carefully optimized for the determination of TEL. Analytes were detected by tandem mass spectrometry using MRM of precursor-product ion transitions with $0.146 \mathrm{~s}$ dwell time, at $m / z 515.27>276.13$ for TEL and $\mathrm{m} / \mathrm{z} 350.1>156.0$ for IS. A standard solution $(100 \mathrm{ng} / \mathrm{mL})$ of TEL and the IS were directly infused along with the mobile phase into the mass spectrometer with ESI as the ionization source. The mass spectrometer was tuned initially in both positive and negative ionization modes for TEL. It was observed that the signal intensity of positive ion was much higher than that of negative ion.

Parameters, such as capillary and cone voltage, desolvation temperature, ESI source temperature and flow rate of desolvation gas and cone gas, were optimized to obtain the optimum intensity of protonated molecules of TEL and IS for quantification. Among the parameters, capillary and cone voltage, especially cone voltage, were important parameters. The precursor ion intensities increased significantly when cone voltage was raised gradually. Lastly, analytes produced the strongest ion signals when cone voltage was set up at $72 \mathrm{~V}$. The cone voltage was optimized using cone ramp $(0-100) \mathrm{V}$. The collision energy was investigated from 2 to $80 \mathrm{eV}$ to optimize the response of product ion, and the best values were found to be $50 \mathrm{eV}$ for the chosen product ions $m / z 276.13$. For IS, spectra at $\mathrm{m} / \mathrm{z} 156.0$ was produced at optimum collision energy of $48 \mathrm{eV}$.

Selectivity of the method was assessed by comparing the chromatogram of blank plasma with the corresponding spiked LLOQ sample. Six different batches of blank human plasma were tested to identify the peaks due to the possible biogenic plasma components. Thus the method looks to be selective enough for determination of TEL and IS in plasma. The linearity of the method was determined by a weighted least square regression analysis of standard plot associated with a nine-point standard curve. The calibration curves were generated by plotting area ratio (TEL/IS) as a function of TEL concentration. Representative LLOQ was sensitive enough to investigate the pharmacokinetic behavior of TEL in human plasma. These results indicate that the method has good precision and accuracy and are within the acceptance limit of $<15 \%$ and $\pm<15 \%$ for precision and accuracy respectively. In this study, the matrix effect was evaluated by analyzing MQC sample.

The stabilities of TEL were investigated at two concentrations of QC samples (low and high concentrations) to cover expected conditions during analysis, storage and processing of all samples, which include the stability data from 
various stability exercises like in-injector, benchtop, freeze/thaw and long-term stability tests. These results conclude that TEL was stable under the set experimental conditions and the dilution of the concentrated plasma sample up to four times maintains legibility and integrity of TEL concentration. This result indicates that the extraction efficiency for TEL using protein precipitation method was satisfactory, consistent and concentration independent.

\section{CONCLUSION}

This study represents the first report describing the determination of TEL in human plasma by UPLC-MS/MS method. The developed method is simple, economical high-throughput and highly sensitive. Run time was only $2.5 \mathrm{~min}$ which is suitable for high-throughput analysis and reduction in the use of organic solvents. The proposed method is practical and should suitable for pharmacokinetic and toxicokinetic studies of TEL in humans.

\section{ACKNOWLEDGEMENT}

The authors would like to extend their sincere appreciation to the Deanship of Scientific Research at King Saud University for funding Research Group no. RG-1435-073.

\section{REFERENCES}

1. Pitt B, Konstam MA. Overview of angiotensin II-receptor antagonists. Am J Cardiol 1998; 82(10A): 47S-49S.

2. Ebner T, Heinzel G, Prox A, Beschke K, Wachsmuth $H$. Disposition and chemical stability of telmisartan 1-Oacylglucuronide. Drug Metab Dispos 1999; 27(10): 1143-1149.

3. Unger $T$. Significance of angiotensin type 1 receptor blockade: why are angiotensin II receptor blockers different? Am J Cardiol 1999; 84(10A): 9S-15S.

4. Yusuf S, Teo KK, Pogue J, Dyal L, Copland I, Schumacher H, Dagenais G, Sleight $P$, Anderson C. Telmisartan, ramipril, or both in patients at high risk for vascular events. N Engl J Med 2008; 358(15): 1547-1559.

5. Schupp M, Janke J, Clasen R, Unger $T$, Kintscher U. Angiotensin type 1 receptor blockers induce peroxisome proliferator-activated receptor-gamma activity. Circulation 2004; 109(17): 2054-2057.

6. Kurade VP, Pai MG, Gude R. RP-HPLC Estimation of Ramipril and Telmisartan in Tablets. Indian J Pharm Sci 2009; 71(2): 148-151.

7. Shen J, Jiao Z, $L i Z D$, Shi XJ, Zhong MK. HPLC determination of telmisartan in human plasma and its application to a pharmacokinetic study. Pharmazie 2005; 60(6): 418-420.
8. Zhang $H$, Jiang $Y$, Wen J, Zhou T, Fan G, Wu Y. Rapid determination of telmisartan in human plasma by HPLC using a monolithic column with fluorescence detection and its application to a bioequivalence study. J Chromatogr B 2009; 877(29): 3729-3733.

9. Zargar S, Wani TA. New UPLC-MS/MS method for simultaneous determination of irbesartan and hydrochlorthiazide in human plasma. J Iran Chem Soc 2014; 11(6): 1579-1586.

10. Zargar S, Wani TA. New UPLC-MS/MS method for simultaneous determination of telmisartan and hydrochlorthiazide in human plasma. Lat Am J Pharm 2014; 33(3): 432-440.

11. Li P, Wang Y, Tang Y, Fawcett JP, Cui Y, Gu J. Determination of telmisartan in human plasma by liquid chromatography-tandem mass spectrometry. J Chromatogr B 2005; 828(1-2): 126-129

12. Hempena C, Glasle-Schwarzb L, Kunz U, Karst $U$. Determination of telmisartan in human blood plasma: Part II: Liquid chromatography-tandem mass spectrometry method development, comparison to immunoassay and pharmacokinetic study. Anal Chim Acta 2006; 560(1-2): 41-49.

13. Chen $B$, Liang $Y$, Wang $Y$, Denga $F$, Zhoua $P$, Guob $F$, Huang L. Development and validation of liquid chromatography-mass spectrometry method for the determination of telmisartan in human plasma. Anal Chim Acta 2005; 540(2): 367-373.

14. Hempena C, Glasle-Schwarzb L, Kunzb U, Karsta U. 2006. Determination of telmisartan in human blood plasma: Part I: Immunoassay development. Anal Chim Acta 540(1-2): 367-373.

15. Russo R, Guillarme D, D TTN, Bicchi C, Rudaz S, Veuthey JL. Pharmaceutical applications on columns packed with sub-2 microm particles. J Chromatogr Sci 2008; 46(3): 199-208.

16. Nguyen $D T$, Guillarme $D$, Rudaz S, Veuthey JL. Fast analysis in liquid chromatography using small particle size and high pressure. J Sep Sci 2006; 29(12): 1836-1848.

17. Mazzeo JR, Neue UV, Marianna K, Plumb RS. A new separation technique takes advantage of sub-2- $\mu \mathrm{m}$ porous particles. Anal Chem 2005; 77: 460A-467A.

18. de Villiers A, Lestremau F, Szucs R, Gelebart S, David F, Sandra $P$. Evaluation of ultra performance liquid chromatography. Part I. Possibilities and limitations. J Chromatogr A 2006; 1127(1-2): 60-69.

19. Wren SA, Tchelitcheff $P$. Use of ultra-performance liquid chromatography in pharmaceutical development. J Chromatogr A 2006; 1119(1-2): 140-146.

20. Wani TA. Highly sensitive ultra-performance liquid chromatography/tandem mass spectrometry method for the determination of abiraterone in human plasma Anal Methods 2013; 5(15): 3693-3699.

21. Novakova L, Matysova L, Solich P. Advantages of application of UPLC in pharmaceutical analysis. Talanta 2006; 68(3): 908-918.

Trop J Pharm Res, March 2015; 14(3): 517 
22. US Food and Drug Administration, Center for Drug Evaluation and Research (CDER). Guidance for industry, Bioanalytical Method Validation-2001. [cited 2014 Oct 30]. 2001 Available from: http://www.fda. gov/downloads/Drugs/.../Guidances/ucm070107.pdf
23. European Medicines Agency, Guideline on bioanalytical method validation-2011 [cited 2014 Oct 30]. Available from: http://www.ema.europa.eu/docs/en_GB/docu ment_library/Scientific_guideline/2011/08/WC500109 686.pdf 